\title{
Correction of deviated nose
}

\author{
Man Koon Suh ${ }^{1}$, \\ Euicheol Jeong ${ }^{2}$ \\ ${ }^{I} J W$ Plastic Surgery Center, Seoul; \\ ${ }^{2}$ Department of Plastic and Reconstructive \\ Surgery, Seoul National University College of \\ Medicine, Seoul, Korea
}

Deviated nose deformities have always been a surgical challenge, and it is essential to achieve both functional and esthetic improvements. Various techniques have evolved over time to correct deviated noses but no one method applies in all cases. Successful correction requires a complete understanding of the various surgical techniques and concepts, including the three-dimensional nasal structure and the time-related changes to surgically-treated noses.

Keywords: Acquired nose deformity / Nasal septum / Rhinoplasty

\section{INTRODUCTION}

A deviated nose is a common problem among patients for both functional and esthetic reasons. This term encompasses all clinical conditions involving deviation of the nasal pyramid from the midline of the face. This condition is caused by trauma from acquired injuries, such as from sports or traffic accidents, or congenital deformity. In clinical practice, neglected nasal fractures frequently result in a deviated nose associated with surface depressions and irregularities. Recently, there has been an increase in inadequate iatrogenic trauma, creating severe deviation after primary septorhinoplasty [1-3].

The septal condition mostly controls the direction of deviation. Trauma creates the extrinsic forces that are exerted on the septum, resulting in deviated nasal bones, upper lateral cartilages, and connections with the vomer, ethmoid, and maxillary crest. Intrinsic forces can be the result of imperfect growth of the septal cartilage or from trauma altering the tissue ultrastructure, after which the deviated cartilaginous tissue has a tendency to revert to its initial position. The resulting deviation can be linear I-shaped, Cshaped, or S-shaped (Fig. 1). One side of the dorsum in a C-shaped nose is concave and the other is convex. The dorsum and tip in an

\section{Correspondence: Euicheol Jeong}

Department of Plastic Surgery, SMG-SNU Boramae Medical Center, 20 Boramae-ro 5-gil, Dongjak-gu, Seoul 07061, Korea

E-mail: ecjeong@snu.ac.kr

Received May 18, 2018 / Revised June 8, 2018 / Accepted June 8, 2018
I-shaped crooked nose (linear) are shifted to one side of the vertical midline of the face [2].

Precise analysis of a deviated nose is the initial step in determining optimal management. Facial asymmetries and paralysis must be considered when dealing with the nose. To analyze the face, a vertical line is drawn from the exact midpoint between the medial canthi, as well as a horizontal line passing through both medial canthi (Fig. 2). Using these reference lines, facial asymmetries in the nasal axis should be obvious. Facial palsy also changes the facial axis in facial expression. These conditions should be conveyed to the patient preoperatively because they can cause the postoperative result to be suboptimal [4].

Nasal analysis begins by noting the deviation of the nose from the facial midline. Beginning with the upper third of the nose, the width of the bony pyramid is assessed, as is the length of the nasal bones, because asymmetric nasal bones will require asymmetric hump reduction to prevent foreshortening of the more vertically oriented nasal bone on the side of the convexity [4].

The analysis should continue with evaluation of the symmetry of the middle third. The relationship of the upper lateral cartilage with the nasal bones should be determined, particularly if there is any narrowing, step-off deformity, or skewing. Scarring or warping in the middle vault is also assessed. The septum is analyzed for deviations, particularly those deflections that are high dorsal or caudal. The area of the internal nasal valve is of great importance in this region, and is formed by the caudal free edge of the upper 

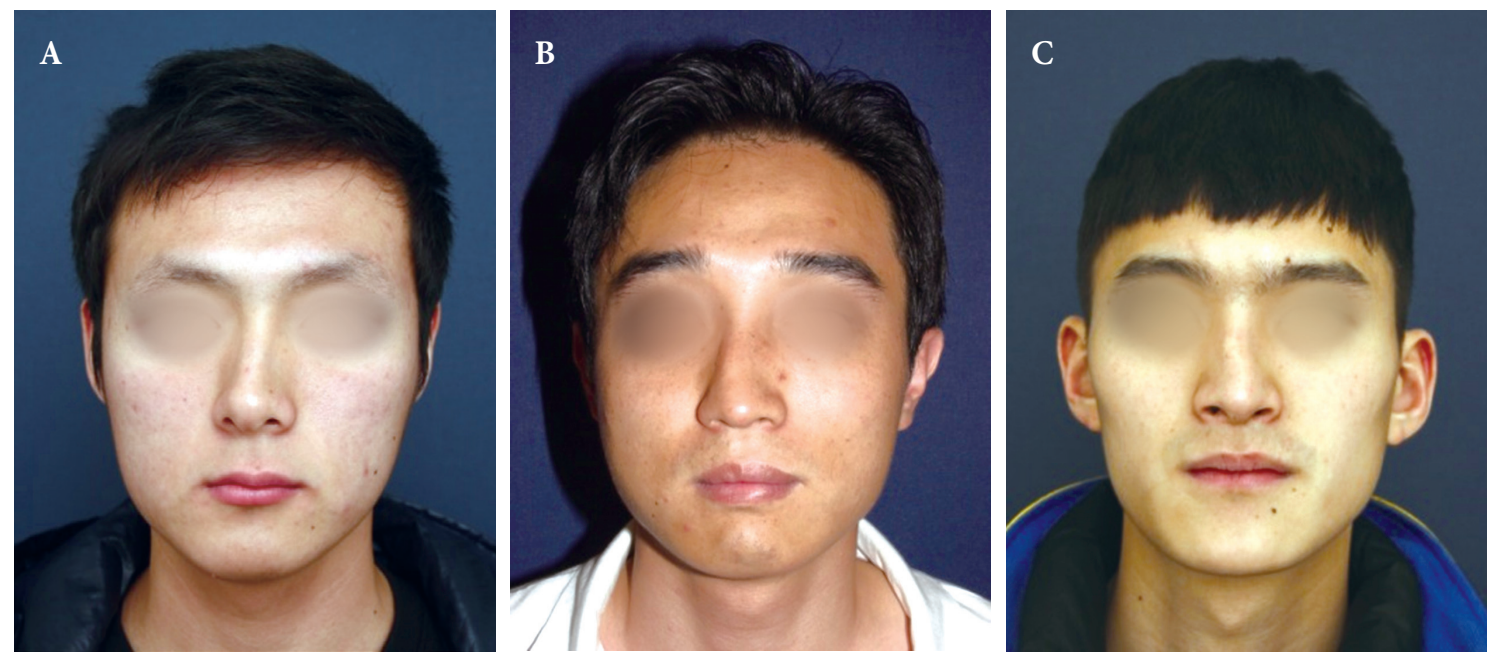

Fig. 1. The patients with deviated nose. (A) I-shaped deviation. (B) C-shaped deviation. (C) S-shaped deviation.

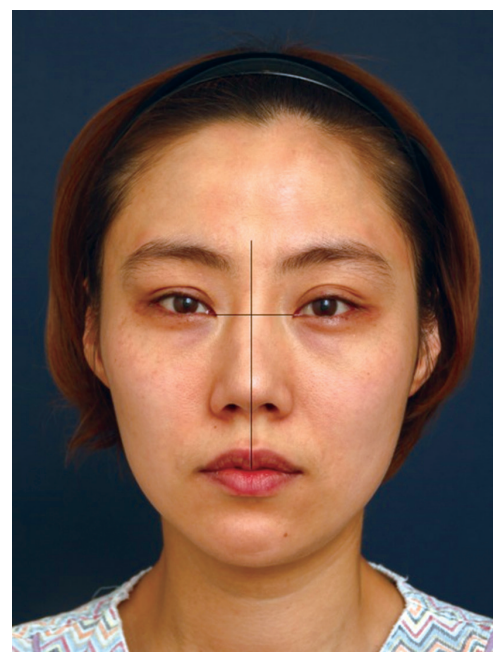

Fig. 2. The vertical and horizontal lines for analysis of deviated nose.

lateral cartilage, the septum, and the nasal floor. Any angle of less than $10^{\circ}$ may result in nasal airway obstruction $[5,6]$. Hypertrophic turbinates and polyps disturb the nasal airways. Simple Xrays and computed tomography scans are usually checked as part of a radiological study to help verify septum and turbinate anomalies, such as concha bullosa and septa bullosa $[7,8]$.

The lower third of the nose includes the medial, middle, and lateral crura of the lower lateral cartilages. Asymmetry due to septal deformity in this area is determined by skewing the tip-defining points from the horizontal. The caudal edge of the septum may be apparent because it protrudes into either nostril, and the lower lateral cartilages may also have intrinsic deformities that lead to asymmetry [9].

\section{INCISIONS AND EXPOSURE}

Surgeons prefer the exposure technique for corrective rhinoplasty. The endonasal approach has limitations regarding the width of the operation field, but has better postoperative scars. In many East Asian patients, whose noses are smaller, it is not comfortable to manipulate the cartilage with graft and suture techniques using the endonasal approach. The authors prefer the open rhinoplasty approach when correcting deviated noses that require extensive septal correction and multiple cartilage grafting and suture techniques (Fig. 3).

\section{PROCEDURE FOR THE MIDDLE VAULT (CARTILAGINOUS DORSUM) AND SEPTUM}

As the septum goes, so goes the nose, stressing the importance of septal correction. Severe deformities or deviations of the dorsal and caudal septum (which determine, to a large degree, nasal shape and position) require extensive septal manipulation facilitated by individualized exposure. A hemitransfixion or even open transcolumellar approach with a complete bilateral mucoperichondrial elevation may be necessary. Sometimes surgical tech- 


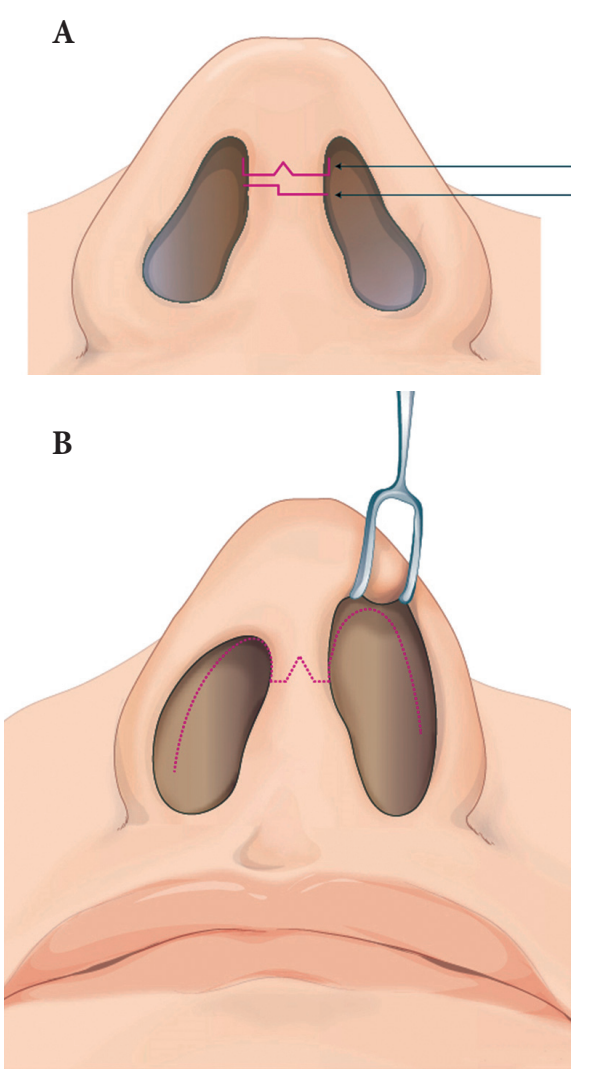

Fig. 3. Open rhinoplasty incision. (A) Transcolumellar incision with inverted V (above arrow) or stair step fashion (below arrow). (B) Marginal incision extended from transcolumellar incision.

niques for realignment (suture fixation, locking, and cartilage shaving) combined with weakening (resection, through and through incisions, scoring, and morselization) and subsequent reconstruction (suture approximation and dorsal and caudal battens) reflect the emphasis on preservation of cartilaginous tissue. Relocation of a dislocated septum back onto the crest is important. If necessary, the caudal septum should be sutured to the periosteum at the nasal spine to prevent lateral migration. These procedures provide a straight foundation to the cartilaginous dorsum and columella, solve the functional problem, and provide the cartilage for grafting during rhinoplasty [10].

Many techniques described in the literature involve the use of sections, incisions, and morselization to modify the cartilaginous portion of the dorsal pillar of the septum and straighten the nose $[10,11]$. Unfortunately, these methods are often unsuccessful due to the memory effect of the cartilage warping and excessive weak- ening of the supporting structure, leading to the collapse of the nasal dorsum.

The use of spreader grafts allowed considerable progress toward correction of dorsal deviations. The original technique devised by Sheen [12] in 1984 involved positioning a rectangular strip of cartilage on either side of the dorsal septum that had been harvested from its central part. This surgical technique involves a classical septoplasty, leaving in place an L-shaped structure (Lstrut) of at least $10 \mathrm{~mm}$ in width, and the harvesting of a straight strip about 3-6 $\mathrm{mm}$ in height from the septum. A septoplasty with an L-strut is usually performed before a nasal osteotomy, but spreader graft and suture in-placement should be done after the osteotomy. This method fundamentally serves to strengthen the middle nasal vault, and hence prevents postoperative collapse. It also proves immediately functionally better by broadening the angle of the internal nasal valve, thus increasing respiratory airflow (Fig. 4).

A spreader graft is placed on the concave side in C-shaped deviations to restore respiratory function and to enhance the dorsal esthetic line. In cases of linear deviation, the spreader graft is placed on the side opposite to the deviation, where there is a gap between the septum and the upper lateral cartilages. In both cases, use of spreader grafts enables a lasting correction of the deviation and camouflaging of any residual deviation. The use of bilateral spreader grafts firmly secures the septum in position and counters any deviations caused by the septal cartilage memory. The spreader grafts are fixed between the dorsal margin of the cartilaginous septum and the upper lateral cartilages.

In hump reduction cases, the cartilaginous hump is corrected prior to the septoplasty so as to preserve the sufficient width of dorsal septum after removing the cartilaginous hump. The excessive bilateral upper lateral cartilages may be used like a spreader graft in the form of an autospreader flap [13].

\section{NASAL OSTEOTOMY}

A greenstick fracture may result if only lateral osteotomies are performed because a bony bridge remains from the end of the lateral osteotomy to the root of the nose. Greenstick fractures are not 

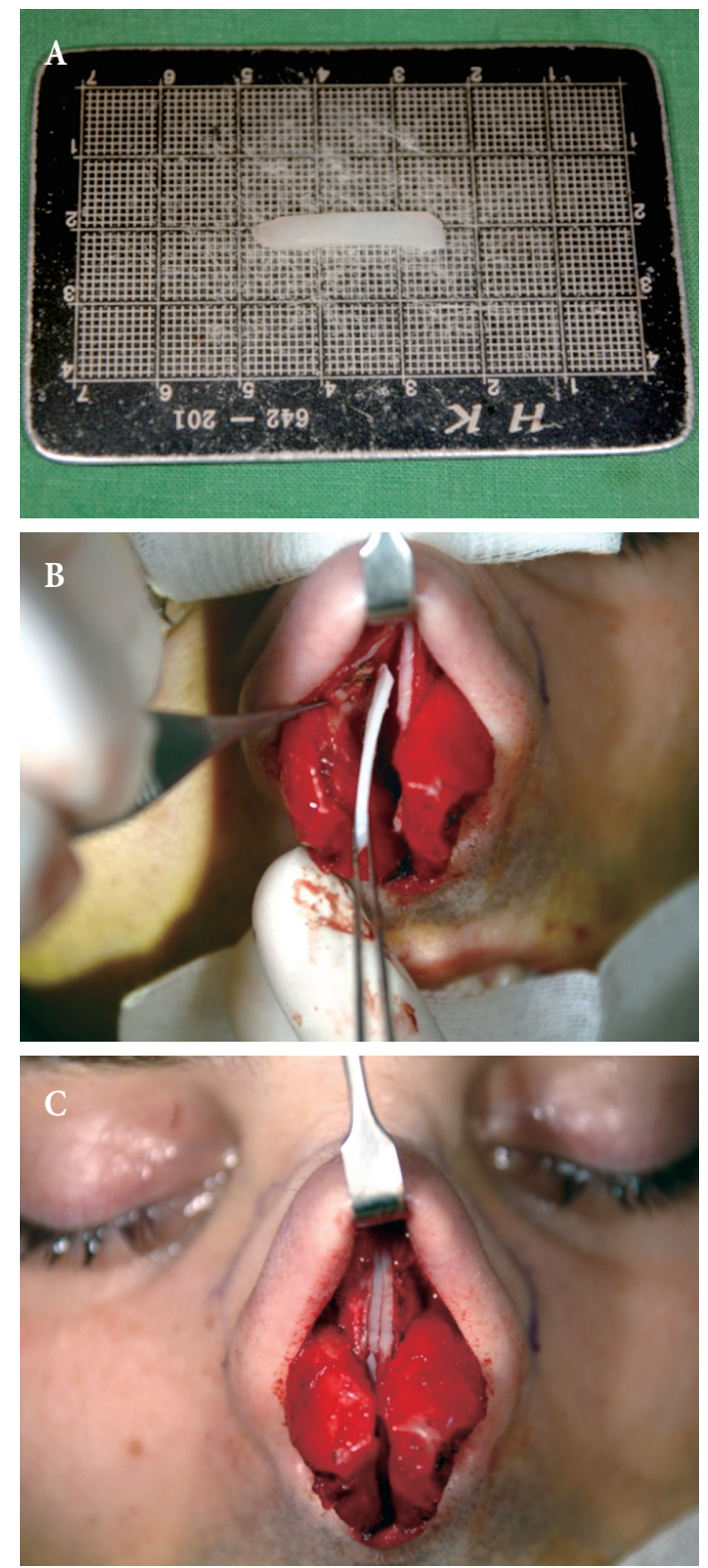

Fig. 4. Spreader graft using septal cartilage for the internal valve insufficiency of right side. (A) Straight strip from septal cartilage for spreader graft. (B) The graft placed between right upper lateral cartilage and septum. (C) The graft corrects the dorsal septal deviation and improves the respiratory function.

ideal because they result in a postoperative return of the bony pyramid to its original configuration [14].

Medial and lateral osteotomy is performed in the unilateral or bilateral osteotomy fashions for direct modification of nasal bone position. Several modifications are possible depending on the patients' individual status by deformities. Unilateral osteotomies can be performed in many cases of deviated nose. Internal and external approaches to osteotomy are commonly used according to the surgeon's preference. Whatever is chosen, the Webster's triangle at the lower end of the pyriform aperture should be preserved (Fig. 5) and rocker deformity avoided (Fig. 6) [14,15].

In severe cases of deviation, a percutaneous root osteotomy may be performed. In this maneuver, a 2-mm osteotome is used to make perforated percutaneous osteotomies in a horizontal fashion across the nasion, or just inferior to the nasal root. This series of perforations should connect the most cephalic aspect of the lateral osteotomies and provide great mobility when combined with medial and lateral osteotomies. The bony dorsum can be manipulated and molded with the opposite hand in place. This maneuver is sometimes used when medial and lateral osteotomies are insufficient [16].

The bony hump is removed before nasal osteotomy. The beveled and oblique osteotomy of the bony hump is indicated according to the asymmetry of both nasal bones by deviation deformity. If the patient has a wide nasal bone, a low-level lateral osteotomy can be performed to cover the open roof (Fig. 7) [17,18]. However, in most Asian rhinoplasty cases, real bony humpectomy with osteotome or extensive osteotomy is rarely applicable due to the smaller average nasal bone. Rasping of bone or dorsal camouflage grafts, which are more conservative, are done to correct external dorsal appearance in the upper third of the nose (Fig. 8) [19].

\section{CAMOUFLAGE TECHNIQUE}

Fine anatomical grafts to correct superficial irregularities may be performed after dorsal septal axis correction and nasal osteotomy. The conchal cartilage appears to be more suitable and can be easily harvested, preferably via a simple posterior approach with a minimal scar. The remaining pieces of septal cartilage after septal work are also useful. They are morselized and applied to improve dorsal esthetic lines and correct minor depressions [20,21].

\section{TIP PLASTY}

In deviated nose cases, tip enhancement is not often a major 
A
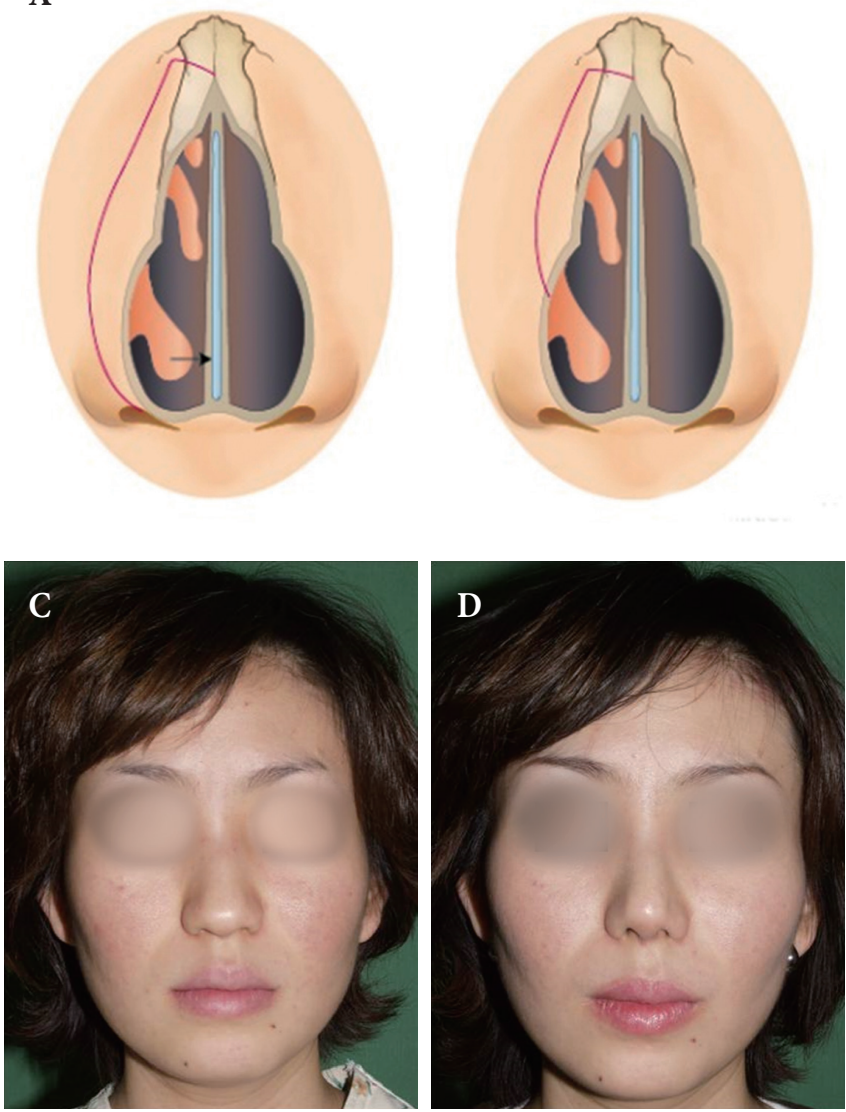
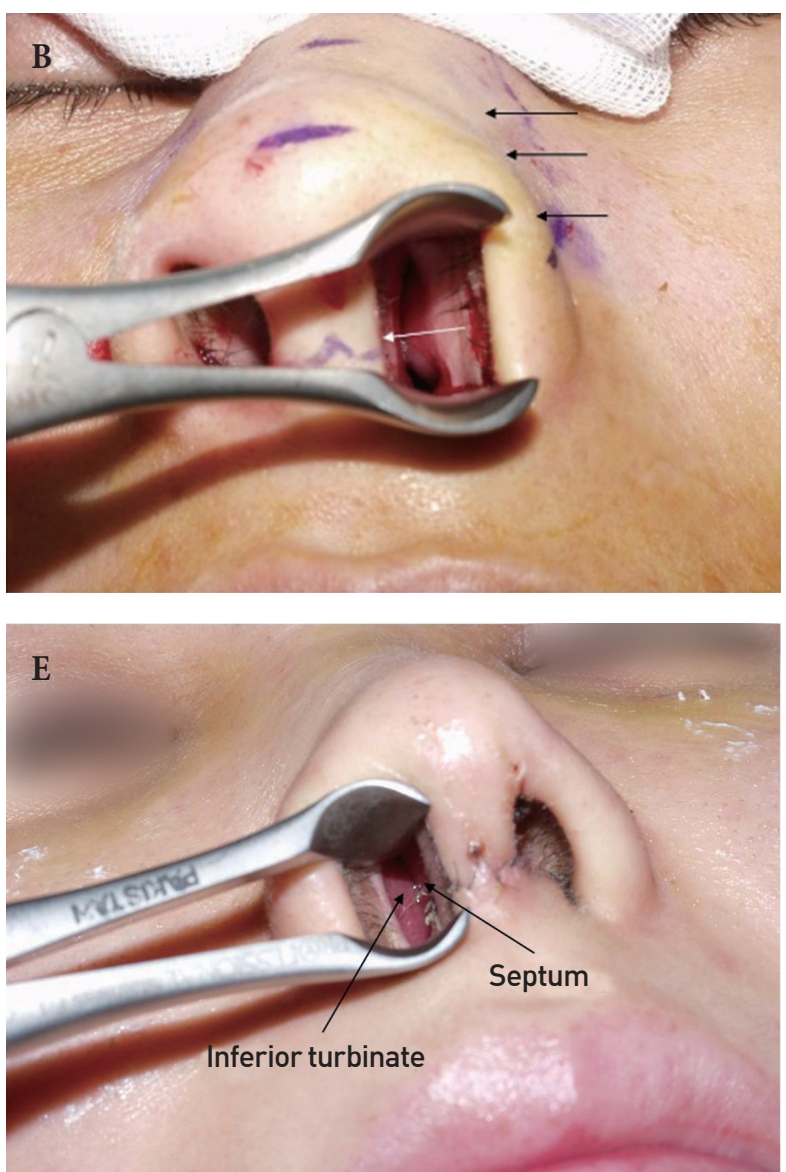

Fig. 5. Lateral osteotomy and inferior turbinate. (A) Inferior turbinate mobilization by the lateral osteotomy. (B) Inward mobilization of inferior turbinate according to lateral osteotomy. (C) Preoperative view of the patient with wide nasal bone. (D) Postoperative view after lateral osteotomy. (E) Inferior turbinate kissing the septum in this case.
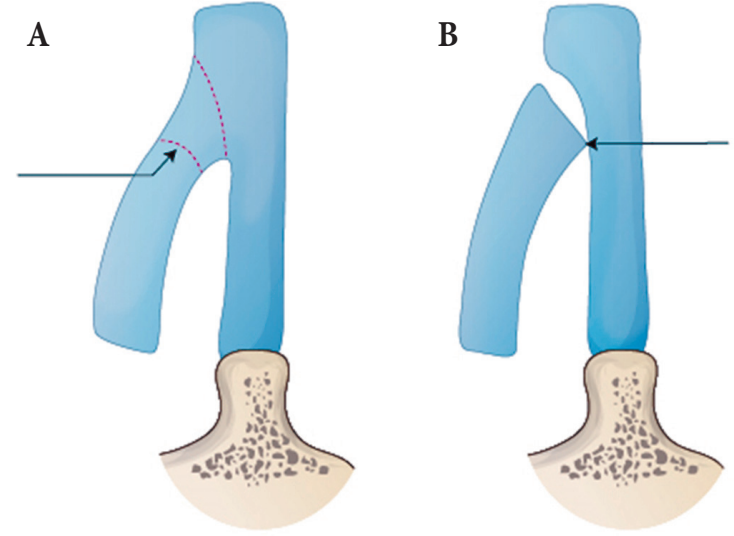

Fig. 6. Rocker deformity. (A) Correct medial osteotomy line (arrow). (B) The bone above the nasion to protrude (arrow).

concern for patients. More esthetic results require a focus on the correction of the tip and columella deviation as well as bony and mid-vault framework deviation. The asymmetric tip and nostril do not merely come from the asymmetric lower lateral cartilages, but from the deviated septum. Most cases of deviated tips and columella and nostril asymmetry are closely related to the deviated caudal and dorsal septum. Therefore, correction of columella and nostril asymmetry means correction of the caudal and dorsal septum as well as of the lower lateral cartilage asymmetry (Fig. 9).

The tip structure must be strong enough to support the weight of the skin and retraction forces in the normal scarring process. Once tip modifications are completed via suture techniques and columella strut graft, further dorsal onlay grafting may be accomplished. A "septal extension graft" can be used to very strongly control the projection and rotation of the nasal tip $[22,23]$. 
A
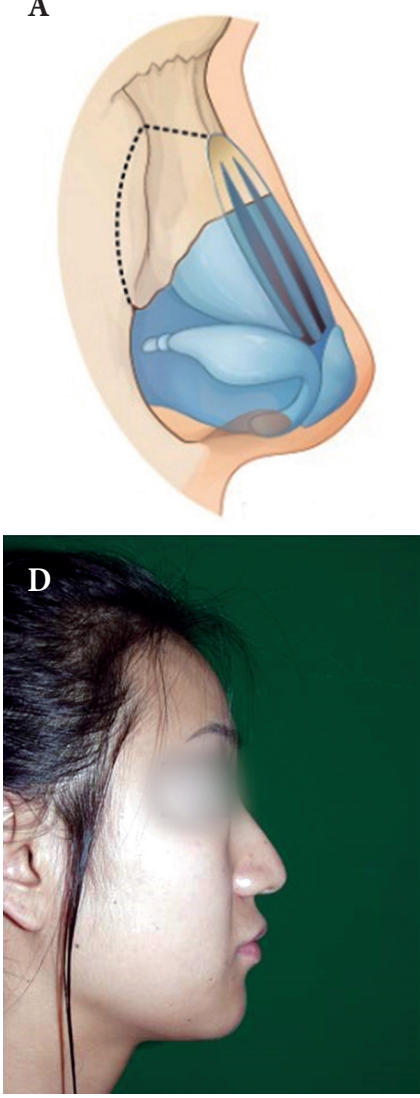

B
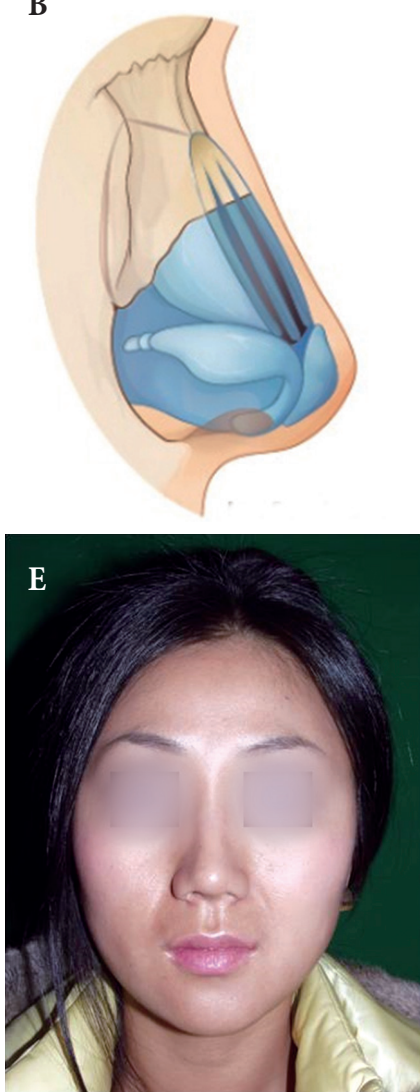

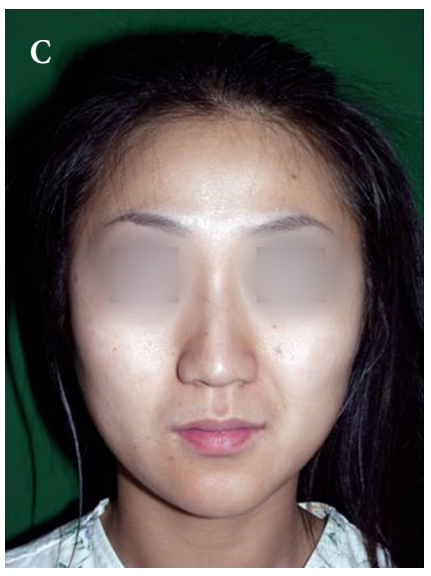

F

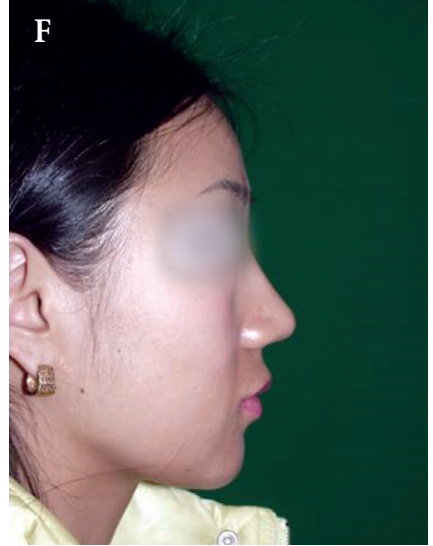

Fig. 7. Open roof closure by lateral osteotomy. (A) Open roof after humpectomy. (B) Open roof closure by lateral osteotomy. (C, D) Preoperative and (E, F) postoperative views.

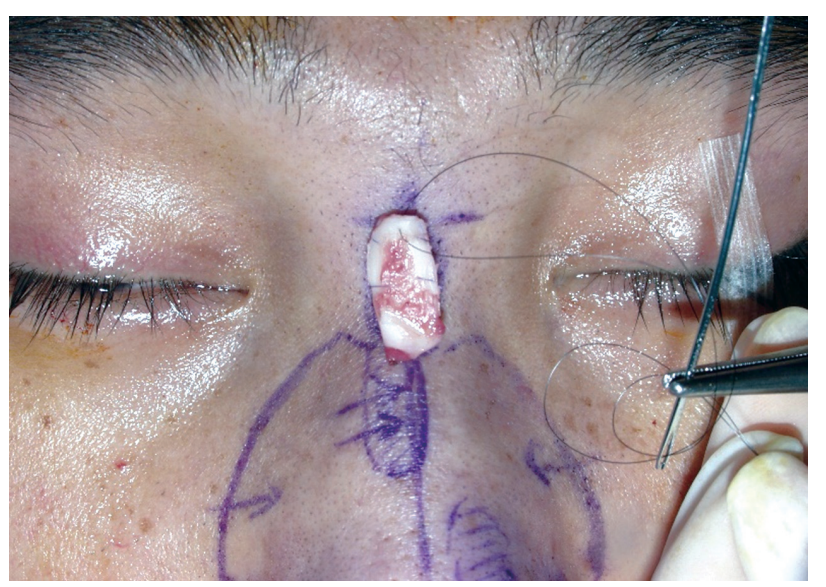

Fig. 8. Graft on radix with the conchal cartilage.

A variety of structural cartilage grafts have been introduced to support the weakened lateral nasal wall of the external valve region: the alar rim graft, lateral crural onlay graft, lateral crural strut graft, and alar batten graft [21,23].

\section{ALLOPLASTIC AND HOMOLOGOUS MATERIAL}

Dorsal augmentation with autogenous tissue is typically preferred because the nasal mucosa is easily injured by instruments and surgical dissections in deviated nose patients, so an independent pocket for alloplastic materials separated from the nasal cavity cannot be obtained. Despite their reputed tendency to be resorbed and deformed over time, various dorsal implants are the graft of choice with excellent results in Asian patients, who have thicker dorsal skin and support implants better than Caucasians. If an alloplastic dorsal implant is used, any tearing of nasal mucosa should be avoided. Most surgeons don't generally accept the use of homologous cadaver grafts for treating de- 

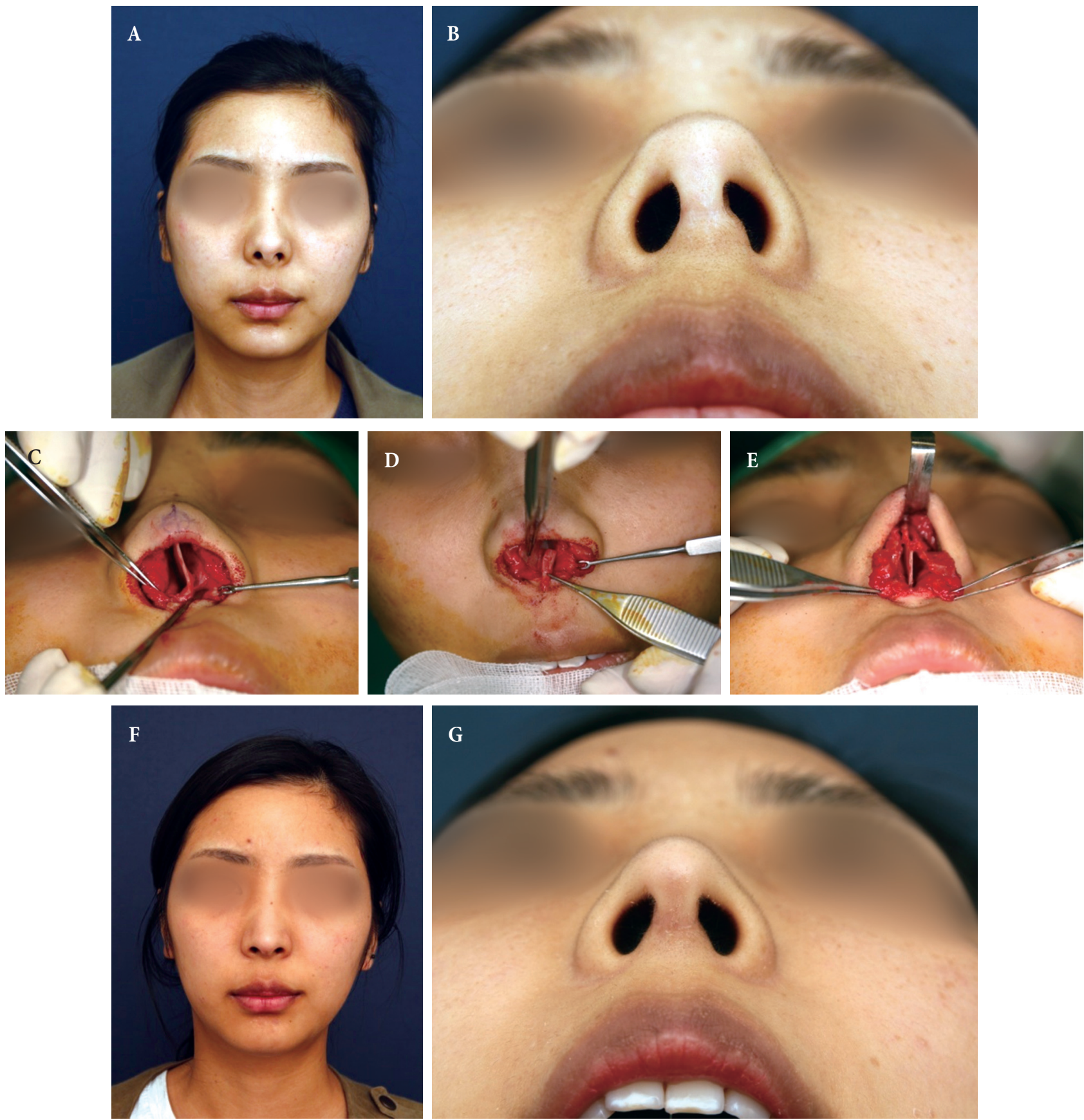

Fig. 9. Correction of deviated caudal septum. (A, B) This female patient has upturned nasal tip due to scar contracture from the previous failed rhinoplasty, and she also has columellar deviation and nostril asymmetry. (C) Caudal septum is deviated toward left side and posterior end of the septum sits on the anterior nasal spine. (D) Excess length of the caudal septum is being shortened by segmental resection of the caudal septal cartilage. (E) Caudal septum became straight. (F, G) Postoperatively, her nasal tip and columella are in the midline without deviation and nostril achieved symmetry. Also, contracted short nose has been corrected by performing the septal extension graft with septal cartilage.

viated noses because of many reports of extrusion and infection

NASAL SPLINTING

[24].

Paper plasters and dorsal splints stabilize and compress the oste- 
otomy site for the prevention of swelling and hematomas. The splints and tapes are removed after 7 days. Intranasal silicone sheets to keep the repositioned septal structures in the midline should be retained for 1-3 weeks according to stability of the septum. Intranasal packing with Merocel or antibiotic ointment imprinted mesh gauzes should be used for 2-3 days to prevent a septal hematoma (Fig. 10). During the period of use of intranasal packing, systemic antibiotics should be used to avoid toxic shock syndrome [25].

\section{CONCLUSIONS}

Deviated noses present a difficult challenge in Asian patients, who have small noses and thick nasal skin. Advanced surgical techniques now make it possible to apply procedures to decrease the most common past complications, such as insufficient treatment, structural weakening, and relapse.
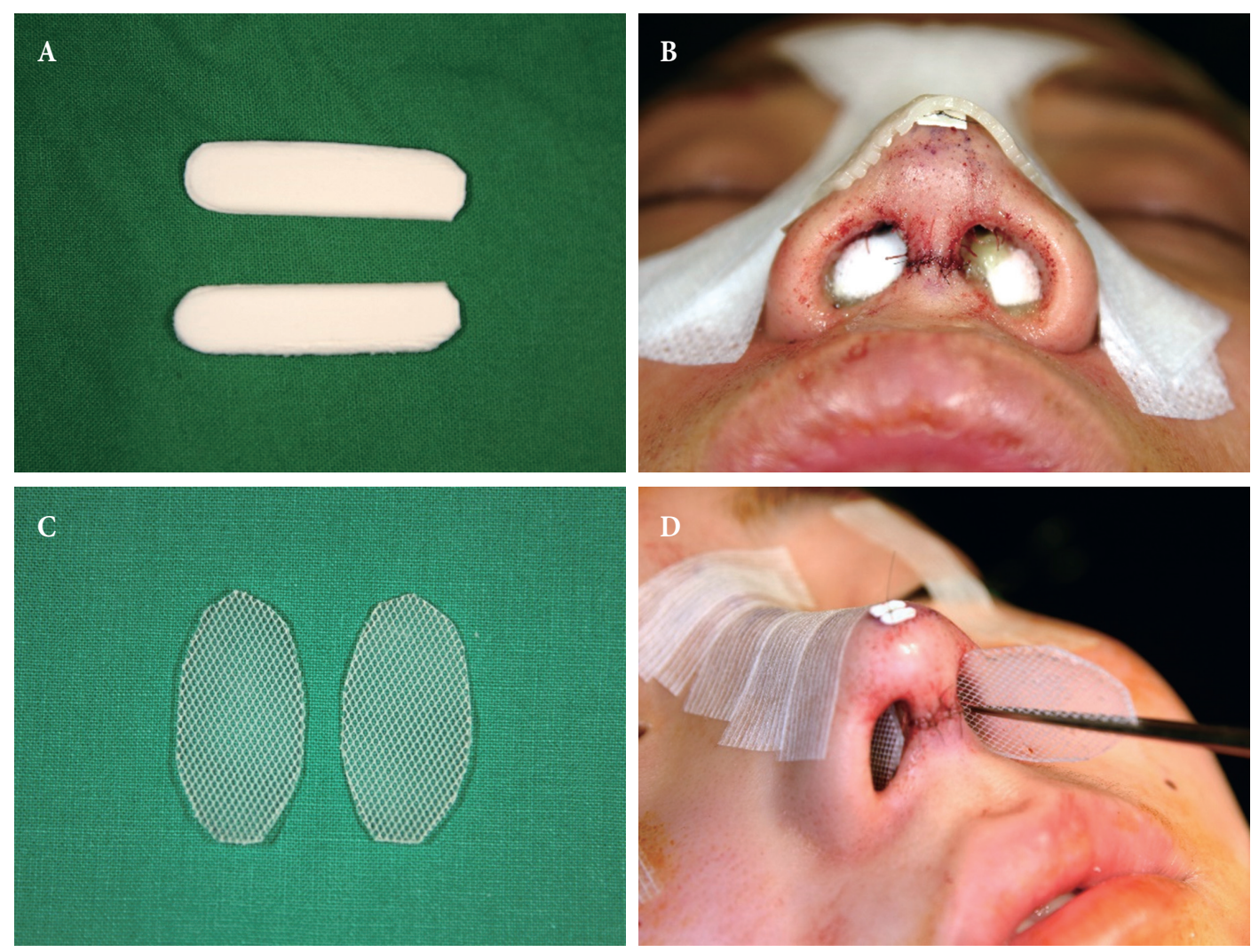

Fig. 10. Nasal splinting and intranasal packing. (A, B) Intranasal packing after septal cartilage harvest. (C, D) Silicone sheets for prevention of mucosal synechia between septum and turbinate. 


\section{REFERENCES}

1. Rohrich RJ, Gunter JP, Deuber MA, Adams WP Jr. The deviated nose: optimizing results using a simplified classification and algorithmic approach. Plast Reconstr Surg 2002;110:1509-23.

2. Jang YJ, Wang JH, Lee BJ. Classification of the deviated nose and its treatment. Arch Otolaryngol Head Neck Surg 2008;134:311-5.

3. Teixeira J, Certal V, Chang ET, Camacho M. Nasal septal deviations: a systematic review of classification systems. Plast Surg Int 2016;2016: 7089123.

4. Yi JS, Jang YJ. Frequency and characteristics of facial asymmetry in patients with deviated noses. JAMA Facial Plast Surg 2015;17:265-9.

5. Howard BK, Rohrich RJ. Understanding the nasal airway: principles and practice. Plast Reconstr Surg 2002;109:1128-46.

6. Fischer H, Gubisch W. Nasal valves: importance and surgical procedures. Facial Plast Surg 2006;22:266-80.

7. Stallman JS, Lobo JN, Som PM. The incidence of concha bullosa and its relationship to nasal septal deviation and paranasal sinus disease. AJNR Am J Neuroradiol 2004;25:1613-8.

8. Mehta R, Kaluskar SK. Endoscopic turbinoplasty of concha bullosa: long term results. Indian J Otolaryngol Head Neck Surg 2013;65(Suppl 2):251-4

9. Constantine FC, Ahmad J, Geissler P, Rohrich RJ. Simplifying the management of caudal septal deviation in rhinoplasty. Plast Reconstr Surg 2014;134:379e-388e.

10. Guyuron B, Uzzo CD, Scull H. A practical classification of septonasal deviation and an effective guide to septal surgery. Plast Reconstr Surg 1999;104:2202-9.

11. Kang JM, Nam ME, Dhong HJ, Kim HY, Chung SK, Kim JH. Modified mattress suturing technique for correcting the septal high dorsal deviation around the keystone area. Am J Rhinol Allergy 2012;26:22732 .

12. Sheen JH. Spreader graft: a method of reconstructing the roof of the middle nasal vault following rhinoplasty. Plast Reconstr Surg
1984;73:230-9

13. Byrd HS, Meade RA, Gonyon DL Jr. Using the autospreader flap in primary rhinoplasty. Plast Reconstr Surg 2007;119:1897-902.

14. VanKoevering KK, Rosko AJ, Moyer JS. Osteotomies Demystified. Facial Plast Surg Clin North Am 2017;25:201-10.

15. Fanous N. Unilateral osteotomies for external bony deviation of the nose. Plast Reconstr Surg 1997;100:115-23.

16. Jang YJ, Wang JH, Sinha V, Lee BJ. Percutaneous root osteotomy for correction of the deviated nose. Am J Rhinol 2007;21:515-9.

17. Bohluli B, Moharamnejad N, Bayat M. Dorsal hump surgery and lateral osteotomy. Oral Maxillofac Surg Clin North Am 2012;24:75-86.

18. Conrad K, Gillman G. Refining osteotomy techniques in rhinoplasty. JOtolaryngol 1998;27:1-9.

19. Jang YJ, Kim JH. Classification of convex nasal dorsum deformities in Asian patients and treatment outcomes. J Plast Reconstr Aesthet Surg 2011;64:301-6

20. Oreroglu AR, Cakır B, Akan M. Bone dust and diced cartilage combined with blood glue: a practical technique for dorsum enhancement. Aesthetic Plast Surg 2014;38:90-4.

21. Jin HR, Lee JY, Shin SO, Choi YS, Lee DW. Key maneuvers for successful correction of a deviated nose in Asians. Am J Rhinol 2006;20:60914.

22. Ha RY, Byrd HS. Septal extension grafts revisited: 6-year experience in controlling nasal tip projection and shape. Plast Reconstr Surg 2003;112:1929-35.

23. Jin HR, Won TB. Nasal tip augmentation in Asians using autogenous cartilage. Otolaryngol Head Neck Surg 2009;140:526-30.

24. Wee JH, Mun SJ, Na WS, Kim H, Park JH, Kim DK, et al. Autologous vs irradiated homologous costal cartilage as graft material in rhinoplasty. JAMA Facial Plast Surg 2017;19:183-8.

25. Breda SD, Jacobs JB, Lebowitz AS, Tierno PM Jr. Toxic shock syndrome in nasal surgery: a physiochemical and microbiologic evaluation of Merocel and NuGauze nasal packing. Laryngoscope 1987;97:1388-91. 